\title{
Mycoplasmal Pneumonia
}

National Cancer Institute

\section{Source}

National Cancer Institute. Mycoplasmal Pneumonia. NCI Thesaurus. Code C122526.

Pneumonia caused by Mycoplasma pneumoniae. Signs and symptoms include productive cough, fever, chills, shortness of breath, and chest pain. 